\title{
3D shape analyses of extant primate and fossil hominin vertebrae support the ancestral shape hypothesis for intervertebral disc herniation
}

Kimberly A. Plomp ${ }^{1,2}$, Keith Dobney ${ }^{1,2,3}$, Darlene A. Weston ${ }^{4}$, Una Strand Viðarsdóttir ${ }^{5}$ and Mark Collard ${ }^{2 *}$

\begin{abstract}
Background: Recently we proposed an evolutionary explanation for a spinal pathology that afflicts many people, intervertebral disc herniation (Plomp et al. [2015] BMC Evolutionary Biology 15, 68). Using 2D data, we found that the bodies and pedicles of lower vertebrae of pathological humans were more similar in shape to those of chimpanzees than were those of healthy humans. Based on this, we hypothesized that some individuals are more prone to intervertebral disc herniation because their vertebrae exhibit ancestral traits and therefore are less well adapted for the stresses associated with bipedalism. Here, we report a study in which we tested this "Ancestral Shape Hypothesis" with 3D data from the last two thoracic and first lumbar vertebrae of pathological Homo sapiens, healthy H. sapiens, Pan troglodytes, and several extinct hominins.

Results: We found that the pathological and healthy $\mathrm{H}$. sapiens vertebrae differed significantly in shape, and that the pathological $H$. sapiens vertebrae were closer in shape to the $P$. troglodytes vertebrae than were the healthy $H$. sapiens vertebrae. Additionally, we found that the pathological human vertebrae were generally more similar in shape to the vertebrae of the extinct hominins than were the healthy $H$. sapiens vertebrae. These results are consistent with the predictions of the Ancestral Shape Hypothesis. Several vertebral traits were associated with disc herniation, including a vertebral body that is both more circular and more ventrally wedged, relatively short pedicles and laminae, relatively long, more cranio-laterally projecting transverse processes, and relatively long, cranially-oriented spinous processes. We found that there are biomechanical and comparative anatomical reasons for suspecting that all of these traits are capable of predisposing individuals to intervertebral disc herniation.
\end{abstract}

Conclusions: The results of the present study add weight to the hypothesis that intervertebral disc herniation in $\mathrm{H}$. sapiens is connected with vertebral shape. Specifically, they suggest that individuals whose vertebrae are towards the ancestral end of the range of shape variation within $\mathrm{H}$. sapiens have a greater propensity to develop the condition than other individuals. More generally, the study shows that evolutionary thinking has the potential to shed new light on human skeletal pathologies.

Keywords: Back pain, Intervertebral disc herniation, Spine, Vertebrae, Bipedalism, Human evolution

\footnotetext{
*Correspondence: mcollard@sfu.ca

${ }^{2}$ Department of Archaeology, Simon Fraser University, 8888 University Dr,

Burnaby, BC V5A 156, Canada

Full list of author information is available at the end of the article
}

(c) The Author(s). 2019 Open Access This article is distributed under the terms of the Creative Commons Attribution 4.0 International License (http://creativecommons.org/licenses/by/4.0/), which permits unrestricted use, distribution, and reproduction in any medium, provided you give appropriate credit to the original author(s) and the source, provide a link to the Creative Commons license, and indicate if changes were made. The Creative Commons Public Domain Dedication waiver (http://creativecommons.org/publicdomain/zero/1.0/) applies to the data made available in this article, unless otherwise stated. 


\section{Background}

Investigating the causes of back pain is an important undertaking. Up to two-thirds of people experience back pain at some point in their life $[1,2]$, making it one of the most common medical problems. It is also one of the most serious medical conditions. Surveys indicate that back pain is the single greatest contributor to disability worldwide [3] and this has substantial economic impacts [4]. For example, back pain has been estimated to cost the UK between $£ 3$ billion and $£ 12$ billion per year $[5,6]$. The situation is similar in the US, where it has been calculated that corporations currently lose nearly $\$ 7.5$ billion per year due to back pain among workers in the 40-65 year age group [7]. Given the individual and societal costs of back pain, there is a pressing need for further research on its causes.

Modern humans are affected by spinal pathologies more often than other, wild-living animals [8,9] and this has led researchers to propose that our unique mode of posture and locomotion, bipedalism, is one of the factors responsible for back pain [10-15]. Bipedalism, it is argued, places an unusually large amount of stress on the spine that can result in damage to the vertebrae and intervertebral discs [10-15]. While this explanation is intuitively appealing, there has been surprisingly little research on the relationship between spinal pathologies and bipedalism. To date, less than a dozen studies have investigated the topic with data [10-23].

Most of the studies that have examined the relationship between spinal pathologies and bipedalism have focused on spondylolysis, a condition in which a fatigue fracture causes a cleft in the neural arch. Ward et al. [16-18] suggested that susceptibility to spondylolysis is related to an important adaptation for bipedalism, lumbar lordosis, which is a forward curvature of the lower spine. They found that spondylolysis sufferers tend to have reduced medio-lateral spacing between the zygapophyseal facets of adjoining vertebrae, which leads to the articular processes of one vertebra directly contacting the pars interarticularis of the subjacent vertebra, causing the fatigue fracture. In a similar vein, Masharawi et al. [20] discovered that individuals with spondylolysis tend to have more wedge-shaped 5th lumbar vertebrae than unaffected individuals. They suggested that this increases lumbar lordosis and influences the development of spondylolysis by increasing direct contact between the neural arches of the 4th and 5th lumbar vertebrae.

Recently we proposed a link between bipedalism and another common spinal pathology, intervertebral disc herniation [15]. Intervertebral disc herniation can be asymptomatic [24-26] or can result in both acute and chronic episodes of back pain [27-29]. One form of it, vertical intervertebral disc herniation, can be recognized on skeletal remains by the presence of Schmorl's nodes, which are depressions with sclerotic margins on the vertebral endplate (Fig. 1) [30]. We found evidence that Homo sapiens vertebrae with Schmorl's nodes are more similar in shape to the vertebrae of chimpanzees (Pan troglodytes) than are healthy $H$. sapiens vertebrae. Because Homo and Pan share an exclusive common ancestor and there is general agreement that that ancestor was a quadruped (e.g. [31-33]), we proposed that our finding indicated that people who experience intervertebral disc herniation do so because their vertebrae fall at the ancestral end of the range of variation in $H$. sapiens and, therefore, are less well adapted for the stresses associated with bipedalism. We dubbed this the "Ancestral Shape Hypothesis."

While our previous study and those of Ward and colleagues [16-18] and Masharawi et al. [19, 20] support the hypothesis that there is a relationship between spinal pathologies and bipedalism, and suggest that that relationship is mediated by vertebral shape, further work is required. Most obviously, all of the studies in question relied on two-dimensional data [15-20]. Using such data to analyze three-dimensional (3D) anatomical structures can potentially result in traits being missed or mischaracterized, especially when the structures are complex, as is the case with vertebrae [34]. Thus, an issue that needs to be investigated is whether the findings can be replicated when more detailed, 3D data are employed. With this in mind, we carried out a study in which we used 3D geometric morphometric techniques to test the Ancestral Shape Hypothesis for intervertebral disc herniation [15].

Our study focused on the thoracic and lumbar vertebrae of three extant taxa-H. sapiens with Schmorl's nodes, healthy $H$. sapiens, and $P$. troglodytes-and five extinct hominin taxa-Australopithecus africanus, Australopithecus sediba, Paranthropus robustus, Homo naledi, and Homo neanderthalensis. As was the case in our previous study [15], we used the presence of one or more Schmorl's nodes in an individual's vertebral column as evidence of intervertebral disc herniation. We carried out three sets of analyses. In the first, we sought to replicate the results of our previous study [15] and so focused on landmarks of the vertebral body, pedicles, and laminae, and compared the pathological $H$. sapiens vertebrae to the healthy $H$. sapiens and $P$. troglodytes vertebrae. In the second of analyses, we again compared the pathological $H$. sapiens vertebrae to the healthy $H$. sapiens and $P$. troglodytes vertebrae, but this time we included landmarks from other parts of the vertebrae, including the spinous and transverse processes, to obtain a more complete picture of the traits associated with intervertebral disc herniation. In the third and final set of analyses, we compared the pathological $H$. sapiens vertebrae not only to the healthy $H$. sapiens and $P$. troglodytes vertebrae, but also to the 


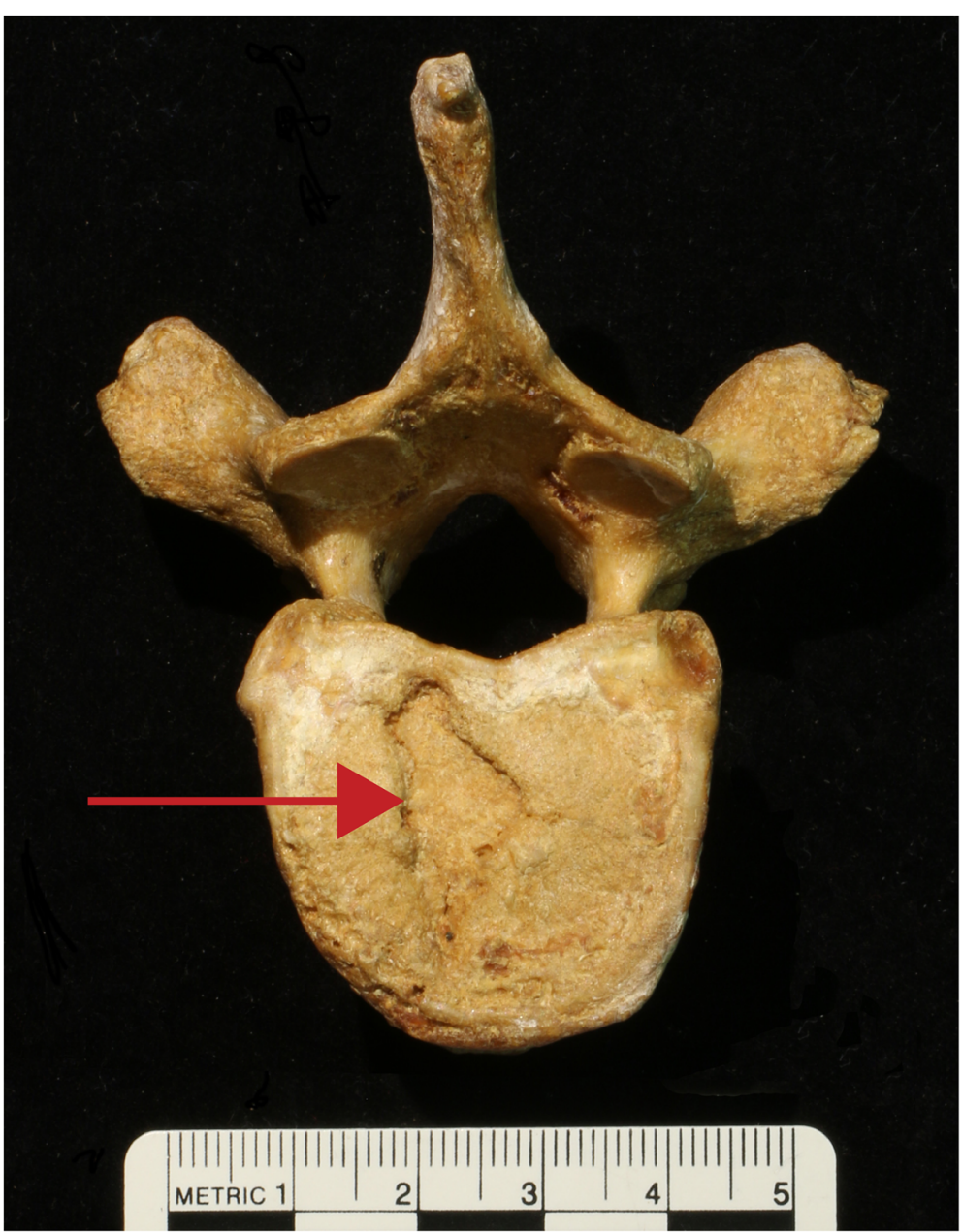

Fig. 1 A Schmorl's node on the inferior endplate of a human thoracic vertebra

vertebrae assigned to the five extinct hominin taxa. In order to minimize the contact with the fragile fossil vertebrae, only the landmarks pertaining to the superior part of the vertebrae were used in this set of analyses.

\section{Methods}

We collected data on the penultimate thoracic, final thoracic, and 1st lumbar vertebrae of $132 \mathrm{H}$. sapiens and 35 P. troglodytes. Fifty-two of the $H$. sapiens specimens had Schmorl's nodes in at least one of their vertebrae, while 80 showed no signs of spinal pathology. Schmorl's nodes were macroscopically diagnosed on the basis of
Schmorl and Junghanns' [24] description. A taxon-bytaxon breakdown of the number of specimens per type of vertebra is given in Table 1 . The number of specimens per vertebral type varies within each taxon because some individuals did not preserve all vertebral types. All specimens were determined to be adult on the basis of epiphyseal fusion [35].

We needed to ensure that the specimens of each vertebra type were homologous. To accomplish this, we categorized vertebrae as thoracic or lumbar based on the orientation of the zygapophyseal facets [36, 37]. There were two reasons for using this definition instead of the

Table 1 Composition of the extant sample. The number of specimens per vertebra type varies within each taxon because some individuals did not preserve all vertebra types

\begin{tabular}{llll}
\hline Taxon & Penultimate thoracic & Final thoracic & First lumbar \\
\hline Pathological Homo sapiens & 43 & 52 & 37 \\
Healthy Homo sapiens & 59 & 66 & 79 \\
Pan troglodytes & 33 & 35 & 33 \\
\hline
\end{tabular}


traditional one in which all vertebra the bear ribs are deemed to be thoracic vertebrae [38-44]. One is that the orientation and curvature of the zygapophyseal facets has been found to be important in posture and locomotion [45-55], making their orientation a critical consideration in this study. The other is that using the "facet definition" allows for the analysis of subtle differences in zygapophyseal shape rather than having the results impacted by the more drastic differences in orientation between thoracic and lumbar facets. In this paper then, "final thoracic vertebra" refers to the diaphragmatic vertebra, which has zygapophyseal joint orientations that are transitional between the thoracic and lumbar spine, with the superior facets exhibiting the thoracic coronal orientation and the lower facets having the lumbar sagittal orientation [46-48]. "Penultimate thoracic" refers to the vertebra that is directly above the diaphragmatic vertebra and has both superior and inferior facets with a thoracic-coronal orientation.

We also collected data on a number of original extinct hominin specimens (Table 2). These included the penultimate thoracic, final thoracic, and 1st lumbar vertebrae of Sts 14, Kebara 2, and Shanidar 3. Sts 14 is a partial skeleton from South Africa that dates to ca. 2.5 Ma and is assigned to Australopithecus africanus [56]. Kebara 2 and Shanidar 3 are $H$. neanderthalensis specimens from sites in the Middle East. Kebara 2 is thought to be around 60,000 years old [57], while Shanidar 3 is estimated to be between 35,000 and 65,000 years old [58]. The other extinct hominin specimens we included in our sample are MH 1, SK 3981a, SK 853, and UW 1011733. MH 1 is a partial skeleton of Australopithecus sediba that was recovered at the site of Malapa, South Africa, and is thought to date to $1.9 \mathrm{Ma}$ [59]. SK 3981a and SK 853 are final thoracic vertebra from the site of Swartkrans, South Africa, that date to around $1.8 \mathrm{Ma}$ and have been assigned to Paranthropus robustus [56]. UW 101-1733 is a penultimate thoracic vertebra assigned to Homo naledi. So far, remains of H. naledi have only been found at the site of Rising Star in South Africa. Like most of the other $H$. naledi specimens, UW 101-1733 has been estimated to date to between 236 and $335 \mathrm{Ka}$ [60]. Based on their degree of epiphyseal fusion, Sts 14, Kebara 2, Shanidar 3, SK3981a, and UW 101-1733 were adults when they died, whereas SK 853 and MH1 were juveniles [56-63]. While the inclusion of juvenile specimens introduced another potential source of error, we opted to do so because well-preserved vertebrae are rare in the hominin fossil record and we wished to maximize the size of our sample.

3D coordinates of 54 landmarks were recorded on each extant vertebra by a single observer (KAP) (Fig. 2). The landmarks were chosen to capture the shapes of the body and posterior elements of the vertebrae and included 32 type II and 22 type III landmarks [64]. Landmarks were recorded using a Microscribe digitizing arm. To reduce the effects of recording error, each vertebra was digitized twice and the coordinates averaged [65].

In order to minimize the risk of damage, only 33 of the landmarks were recorded on the fossil specimens (Fig. 2). The landmarks in question capture the shape of the superior surface of the vertebrae and were chosen because they could be obtained with minimal contact with the specimens. Where necessary, missing landmarks were estimated by mirroring the corresponding landmarks from the opposite side (e.g. the landmark on the left transverse process of the first lumbar of Sts 14 and $\mathrm{MH} 1$ were reflected to estimate the coordinate of the missing landmark of the right process).

Intra-observer error was assessed as per Neubauer et al. [66, 67]. A single first lumbar vertebra was digitized ten times and then Morphologika [68] was used to compare the greatest Procrustes distance between the ten repeated landmark configurations with the ten smallest Procrustes distances between the landmark configurations of all the first lumbar vertebrae. The smallest distance between the non-repeated vertebrae was almost double the greatest distance between the repeated vertebrae. This amount of landmark recording error is considered unlikely to influence the shape variance of the sample $[66,67]$.

Having collected and assessed the accuracy of the data, we carried out three sets of analyses. We began by attempting to replicate our previous results [15]. This involved utilizing only the 26 landmarks pertaining to the body, laminae, and pedicles, and comparing just the extant taxa-pathological $H$. sapiens, healthy $H$. sapiens, and P. troglodytes.

The first step was to remove the effects of translation, rotation, size, and asymmetry from each dataset independently. This was accomplished by applying the approach outlined by Klingenberg et al. [69] to each dataset in turn. This entailed reflecting and re-labelling the landmark coordinates. Each dataset was then subjected to Generalized Procrustes Analysis (GPA), which is designed to remove translational and rotational effects from landmark data and to scale the configurations to centroid size [70]. Subsequently, asymmetry was removed by calculating the average Procrustes coordinates between the original and reflected landmarks [71, 72]. The GPAs were carried out in Morphologika [68], while the averaging of the Procrustes coordinates was performed in Excel.

The next step was to investigate whether the data were affected by a potentially important confounding factorsize-related shape change or "allometry." We did so by subjecting each vertebral dataset to a pooled-taxa regression analysis in which the Procrustes coordinates were 
Table 2 Fossil specimens included in the present study. See main text for references to support putative locomotor strategy assignments

\begin{tabular}{|c|c|c|c|c|c|c|}
\hline Specimen & Taxon & Site & $\begin{array}{l}\text { Estimated } \\
\text { age }\end{array}$ & $\begin{array}{l}\text { Putative } \\
\text { locomotor } \\
\text { strategy }\end{array}$ & Preservation & Curation Location \\
\hline $\begin{array}{l}\text { Kebara } 2 \\
\text { penultimate } \\
\text { thoracic }\end{array}$ & $\begin{array}{l}\text { Homo } \\
\text { neanderthalensis }\end{array}$ & Kebara, Israel & $60 \mathrm{Ka}$ & $\begin{array}{l}\text { Obligate } \\
\text { biped }\end{array}$ & Complete & Tel Aviv University, Israel \\
\hline $\begin{array}{l}\text { Kebara } 2 \text { final } \\
\text { thoracic }\end{array}$ & $\begin{array}{l}\text { Homo } \\
\text { neanderthalensis }\end{array}$ & Kebara, Israel & $60 \mathrm{Ka}$ & $\begin{array}{l}\text { Obligate } \\
\text { biped }\end{array}$ & Complete & Tel Aviv University, Israel \\
\hline $\begin{array}{l}\text { Kebara } 2 \text { first } \\
\text { lumbar }\end{array}$ & $\begin{array}{l}\text { Homo } \\
\text { neanderthalensis }\end{array}$ & $\begin{array}{l}\text { Kebara, } \\
\text { Israel }\end{array}$ & $60 \mathrm{Ka}$ & $\begin{array}{l}\text { Obligate } \\
\text { biped }\end{array}$ & Complete & Tel Aviv University, Israel \\
\hline $\begin{array}{l}\text { MH } 1 \text { first } \\
\text { lumbar }\end{array}$ & $\begin{array}{l}\text { Australopithecus } \\
\text { sediba }\end{array}$ & $\begin{array}{l}\text { Malapa, } \\
\text { South Africa }\end{array}$ & $1.9 \mathrm{Ma}$ & $\begin{array}{l}\text { Facultative } \\
\text { biped }\end{array}$ & $\begin{array}{l}\text { Complete but transverse processes are } \\
\text { asymmetric (see text for details of how we } \\
\text { dealt with this) }\end{array}$ & $\begin{array}{l}\text { Evolutionary Studies Institute, } \\
\text { University of Witwatersrand, } \\
\text { Johannesburg, South Africa }\end{array}$ \\
\hline $\begin{array}{l}\text { Shanidar } 3 \\
\text { penultimate } \\
\text { thoracic }\end{array}$ & $\begin{array}{l}\text { Homo } \\
\text { neanderthalensis }\end{array}$ & $\begin{array}{l}\text { Shanidar, } \\
\text { Iraq }\end{array}$ & $35-65 \mathrm{Ka}$ & $\begin{array}{l}\text { Obligate } \\
\text { biped }\end{array}$ & Complete & $\begin{array}{l}\text { Smithsonian National } \\
\text { Museum of Natural History, } \\
\text { Washington, DC, USA }\end{array}$ \\
\hline $\begin{array}{l}\text { Shanidar } 3 \\
\text { final thoracic }\end{array}$ & $\begin{array}{l}\text { Homo } \\
\text { neanderthalensis }\end{array}$ & $\begin{array}{l}\text { Shanidar, } \\
\text { Iraq }\end{array}$ & $35-65 \mathrm{Ka}$ & $\begin{array}{l}\text { Obligate } \\
\text { biped }\end{array}$ & Complete & $\begin{array}{l}\text { Smithsonian National } \\
\text { Museum of Natural History, } \\
\text { Washington, DC, USA }\end{array}$ \\
\hline $\begin{array}{l}\text { Shanidar } 3 \\
\text { first lumbar }\end{array}$ & $\begin{array}{l}\text { Homo } \\
\text { neanderthalensis }\end{array}$ & Shanidar,Iraq & $35-65 \mathrm{Ka}$ & $\begin{array}{l}\text { Obligate } \\
\text { biped }\end{array}$ & $\begin{array}{l}\text { Nearly complete but some elements } \\
\text { reconstructed }\end{array}$ & $\begin{array}{l}\text { Smithsonian National } \\
\text { Museum of Natural History, } \\
\text { Washington, DC, USA }\end{array}$ \\
\hline $\begin{array}{l}\text { SK } 853 \text { final } \\
\text { thoracic }\end{array}$ & $\begin{array}{l}\text { Paranthropus } \\
\text { robustus }\end{array}$ & $\begin{array}{l}\text { Swartkrans, } \\
\text { South Africa }\end{array}$ & $1.8 \mathrm{Ma}$ & $\begin{array}{l}\text { Facultative } \\
\text { biped }\end{array}$ & $\begin{array}{l}\text { Mostly complete but missing tip of right } \\
\text { transverse process and small portion of } \\
\text { right superior zygapophyseal facet }\end{array}$ & $\begin{array}{l}\text { Ditsong National Museum of } \\
\text { Natural History, Pretoria, } \\
\text { South Africa }\end{array}$ \\
\hline $\begin{array}{l}\text { SK 3981a } \\
\text { final thoracic }\end{array}$ & $\begin{array}{l}\text { Paranthropus } \\
\text { robustus }\end{array}$ & $\begin{array}{l}\text { Swartkrans, } \\
\text { South Africa }\end{array}$ & $1.8 \mathrm{Ma}$ & $\begin{array}{l}\text { Facultative } \\
\text { biped }\end{array}$ & Complete with minor damage to body & $\begin{array}{l}\text { Ditsong National Museum of } \\
\text { Natural History, Pretoria, } \\
\text { South Africa }\end{array}$ \\
\hline $\begin{array}{l}\text { Sts } 14 \\
\text { penultimate } \\
\text { thoracic }\end{array}$ & $\begin{array}{l}\text { Australopithecus } \\
\text { africanus }\end{array}$ & $\begin{array}{l}\text { Sterkfontein, } \\
\text { South Africa }\end{array}$ & $2.5 \mathrm{Ma}$ & $\begin{array}{l}\text { Facultative } \\
\text { biped }\end{array}$ & Complete with minor damage to body & $\begin{array}{l}\text { Ditsong National Museum of } \\
\text { Natural History, Pretoria, } \\
\text { South Africa }\end{array}$ \\
\hline $\begin{array}{l}\text { Sts } 14 \text { final } \\
\text { thoracic }\end{array}$ & $\begin{array}{l}\text { Australopithecus } \\
\text { africanus }\end{array}$ & $\begin{array}{l}\text { Sterkfontein, } \\
\text { South Africa }\end{array}$ & $2.5 \mathrm{Ma}$ & $\begin{array}{l}\text { Facultative } \\
\text { biped }\end{array}$ & Complete & $\begin{array}{l}\text { Ditsong National Museum of } \\
\text { Natural History, Pretoria, } \\
\text { South Africa }\end{array}$ \\
\hline $\begin{array}{l}\text { Sts } 14 \text { first } \\
\text { lumbar }\end{array}$ & $\begin{array}{l}\text { Australopithecus } \\
\text { africanus }\end{array}$ & $\begin{array}{l}\text { Sterkfontein, } \\
\text { South Africa }\end{array}$ & $2.5 \mathrm{Ma}$ & $\begin{array}{l}\text { Facultative } \\
\text { biped }\end{array}$ & $\begin{array}{l}\text { Minor damage to body and undeveloped } \\
\text { left transverse process (see text for details of } \\
\text { how we dealt with this) }\end{array}$ & $\begin{array}{l}\text { Ditsong National Museum of } \\
\text { Natural History, Pretoria, } \\
\text { South Africa }\end{array}$ \\
\hline $\begin{array}{l}\text { UW 101- } \\
1733 \\
\text { penultimate } \\
\text { thoracic }\end{array}$ & Homo naledi & $\begin{array}{l}\text { Rising Star, } \\
\text { South Africa }\end{array}$ & $\begin{array}{l}236-335 \\
\mathrm{Ka}\end{array}$ & $\begin{array}{l}\text { Facultative } \\
\text { biped }\end{array}$ & $\begin{array}{l}\text { Nearly complete; missing distal ends of } \\
\text { spinous and transverse processes }\end{array}$ & $\begin{array}{l}\text { Evolutionary Studies Institute, } \\
\text { University of Witwatersrand, } \\
\text { Johannesburg, South Africa }\end{array}$ \\
\hline
\end{tabular}

regressed on the log of centroid size [70, 73]. We found evidence for allometry in all of the 54 landmark datasets (Additional file 1: Table S1). In light of this, we used MorphoJ [74] to regress the Procrustes coordinates on the log of centroid size in order to generate residuals [15, 73]. The residuals were used in all subsequent analyses.

After minimizing allometry in the datasets, we tested to see if sexual dimorphism was a confounding factor. We did so by iteratively subjecting the residuals for the extant penultimate thoracic, final thoracic, and 1st lumbar vertebrae to principal components analyses (PCA) and then running MANOVAs on the PC scores to test for the existence of differences between sexes. The PCAs were performed in Morphologika [68] and the MANOVAs were carried out in SPSS 25.0 [75]. We found that sexual dimorphism did not influence the $P$. troglodytes samples and it was only a significant factor in the first lumbar vertebra of healthy and pathological $H$. sapiens $(\lambda 0.518$, $\mathrm{F}=2.254, p=0.002)$. Given the limited evidence for sexual dimorphism in vertebral shape in the two taxa, we opted to use pooled-sex datasets in the rest of the analyses.

Once the various potential confounding factors were minimized, we subjected the datasets for the three vertebrae to PCA and Wilks-Lambda MANOVA in order to test predictions of the Ancestral Shape Hypothesis. In order to reduce noise from higher components, we implemented the principal component (PC) reduction procedure outlined by Baylac and Frie $\beta$ [76] and Evin et al. 


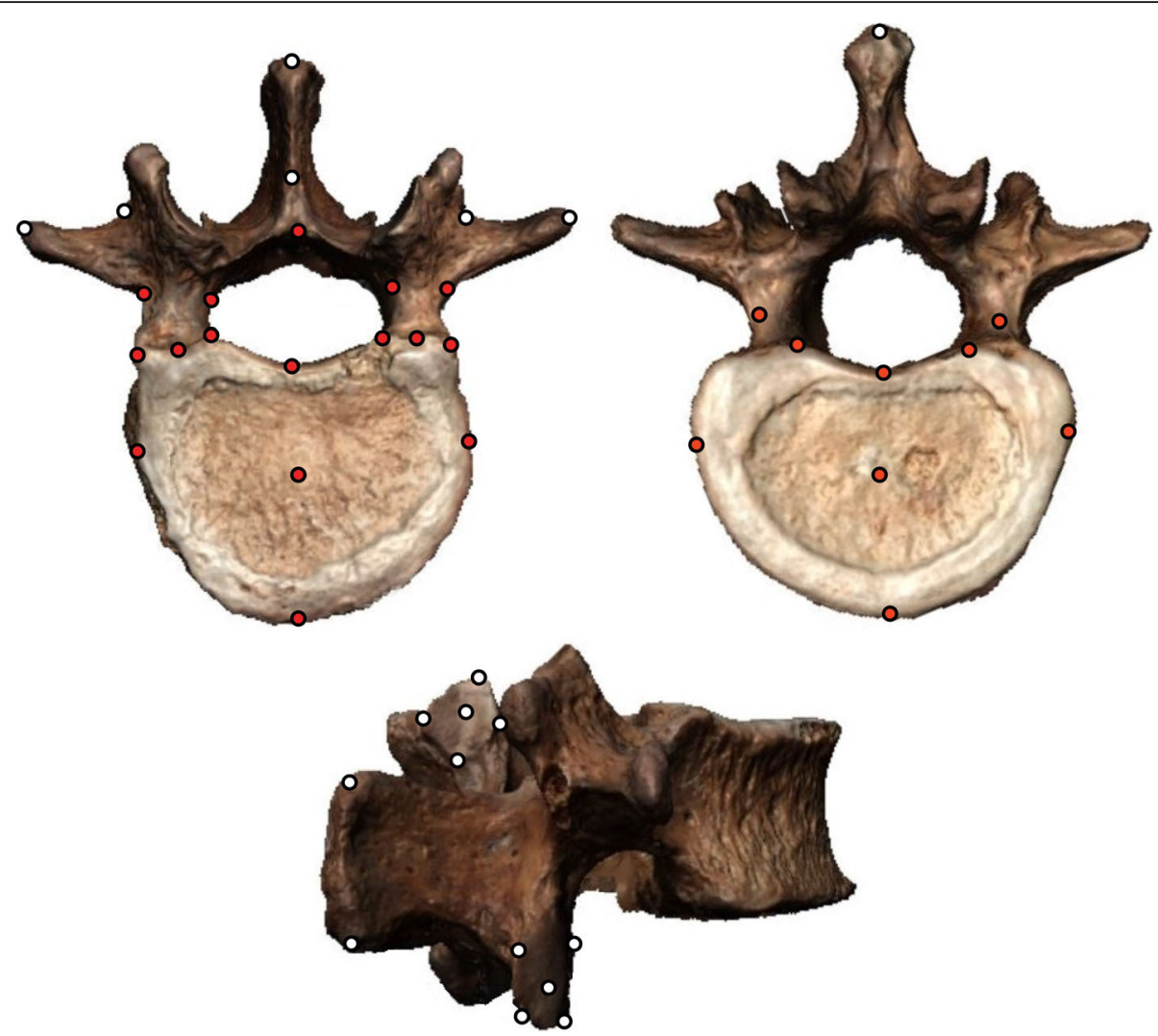

Fig. 2 Landmarks used in the analyses. There are 54 in total. The red ones are the 26 that were used in the first set of analyses. In the third set of analyses, the 33 landmarks on the superior surface of the vertebrae were used. The top-left image is the superior view; the top-right image is the inferior view; and the bottom image is the right lateral view

[77]. This procedure aims to reduce noise from PCs that account for little variance while retaining all relevant shape information. It tackles this optimization problem by progressively adding PCs into the analyses until the cross-validation percentage (CVP) begins to drop. The PCs that had the highest CVP scores while representing a minimum of $95 \%$ of the shape variance were retained for further analyses [76, 77]. The retained PCs were used to calculate the Procrustes distances between the mean shapes of the three groups. Lastly, we applied MANOVAs to the retained PCs to assess the significance of the differences among the taxa. We tested two predictions. One was that there should be a significant difference in shape between the pathological and healthy $H$. sapiens vertebrae. The other was that the pathological $H$. sapiens vertebrae should be closer in shape to the $P$. troglodytes vertebrae than are the healthy $H$. sapiens vertebrae. The PCAs were performed in Morphologika [68], the Procrustes distances were calculated in R [78], and the MANOVAs were carried out in SPSS 25.0 [75].

The second set of analyses was identical to the first set except it used all 54 landmarks rather than just the 26 landmarks pertaining to the body, laminae, and pedicles.
The test predictions were also the same as in the first set of analyses.

In the third set of analyses, we included the fossil specimens as well as the extant ones. This necessitated reducing the landmarks to the 33 available for the fossils. The test predictions took into account what is known about the locomotor repertoires of the extinct species. The current consensus is that $A$. africanus, A. sediba, $P$. robustus, and $H$. naledi were facultative bipeds that walked on two legs when on the ground but routinely engaged in arboreal climbing, whereas $H$. neanderthalensis was an obligate biped like $H$. sapiens [69, 79-86]. Given this, we tested three predictions. The first was that the pathological $H$. sapiens vertebrae should be closer in shape to the $P$. troglodytes vertebrae than are the healthy $H$. sapiens vertebrae. The second was that the pathological $H$. sapiens vertebrae should be more similar to the $A$. africanus, $A$. sediba, $P$. robustus, and $H$. naledi vertebrae than are the healthy $H$. sapiens vertebrae. The third prediction was that the pathological $H$. sapiens vertebrae should be equally similar to the healthy $H$. sapiens and $H$. neanderthalensis vertebrae. To test these predictions, we used the PC scores to calculate the Procrustes distances between the means of the 
extant taxa and the individual fossil specimens. As in the previous Procrustes distance analyses, only the PCs that best discriminated between groups and represented a minimum of $95 \%$ of the shape variance were utilized, and the Procrustes distances were calculated in R [78].

\section{Results}

\section{Analyses using extant taxa and 26 landmarks}

The results of the first set of analyses are summarized in Table 3. The Procrustes distances and MANOVAs indicate that there are significant shape differences between the pathological and healthy $H$. sapiens vertebrae, which is consistent with the first test prediction. The Procrustes distances and MANOVAs are equally clear-cut with regard to the second test prediction. The Procrustes distances between the pathological $H$. sapiens and the $P$. troglodytes vertebrae are consistently smaller than those between the healthy $H$. sapiens and P. troglodytes vertebrae, and all three of the MANOVAs indicate that the mean shape of the pathological $H$. sapiens vertebrae is statistically indistinguishable from the mean shape of the $P$. troglodytes vertebrae. Both of these findings are consistent with the second test prediction. Thus, the results of the first set of analyses are consistent with our previous findings [15] in that they support the Ancestral Shape Hypothesis.

\section{Analyses using extant taxa and all landmarks}

Table 4 summarizes the results of the second set of analyses. The Procrustes distances indicate that there are shape differences between the pathological and healthy $H$. sapiens vertebrae, while the MANOVAs indicate that the differences are statistically significant. This is consistent with the first test prediction. The analyses also support the second test prediction. Not only were the Procrustes distances between the pathological $H$. sapiens and $P$. troglodytes vertebrae smaller than those between healthy $H$. sapiens and $P$. troglodytes in all three vertebrae, but also the MANOVAs indicated that there was not a significant shape difference between the penultimate and final thoracic vertebrae of pathological $H$. sapiens and P. troglodytes. As for the first lumbar vertebrae, the MANOVA comparing the pathological $H$. sapiens and $P$. troglodytes vertebrae returned a significant result.

Figures 3, 4, and 5 illustrate the similarities and differences among the three taxa on the basis of the most informative PCs. In each scatter plot, the centre of the distribution of the pathological $H$. sapiens specimens tends to be located between the centres of the distributions of the healthy $H$. sapiens and $P$. troglodytes specimens. The wireframes show that there are commonalities among the three vertebral types in the way that pathological $H$. sapiens vertebrae differ from healthy $H$. sapiens vertebrae. Compared to healthy $H$. sapiens vertebrae, pathological $H$. sapiens vertebrae have shorter pedicles and laminae and smaller vertebral foramina. They also have bodies that are more ventrally wedged and circular in planform. In addition, the transverse processes are longer and project more in both the cranial and lateral directions. Lastly, the spinous processes are longer, more cranially oriented, and have cranio-caudally taller tips. Importantly for present purposes, these traits also differentiate the $P$. troglodytes specimens from the healthy $H$. sapiens vertebrae.

\section{Analyses using fossil and extant taxa and 33 landmarks}

Table 5 summarizes the results of the third set of analyses. The comparisons involving just the extant taxa are consistent with the first test prediction. In all cases, the pathological $H$. sapiens vertebrae are closer to the $P$. troglodytes vertebrae than are the healthy $H$. sapiens vertebrae.

The comparisons involving the fossil specimens are less straightforward with respect to the relevant test predictions. To reiterate, there were two of them. One was that the pathological $H$. sapiens should be closer to $A$. africanus, $A$. sediba, $P$. robustus, and $H$. naledi than are healthy $H$. sapiens. This prediction was supported by all but one of the relevant comparisons. The exception was the comparison involving the $P$. robustus specimen SK

Table 3 Results of the first set of analyses. Procrustes distances and MANOVAs were used to compare pathological H. sapiens vertebrae with healthy $\mathrm{H}$. sapiens and P. troglodytes vertebrae. Procrustes distances were generated from PCs that accounted for $\geq 95 \%$ of the shape variance. These PCs were also used in the MANOVAs. Analyses are grouped on the basis of vertebral type and arranged by the types' position in the vertebral column. PCs = Number of retained PCs plus the percentage of shape variance they explain. PD = Procrustes distance

\begin{tabular}{lllll}
\hline Vertebra & PCs & Comparison & PD & MANOVA \\
\hline Penultimate thoracic & $1-23$ (94.9\%) & Pathological H. sapiens vs Healthy H. sapiens & 0.0319 & $\lambda 0.593, F=2.476, p=0.001^{*}$ \\
& & Pathological H. sapiens vs P. troglodytes & 0.0207 & $\lambda 0.788, F=0.645, p=0.876$ \\
& & 0.0479 & $\lambda 0.411, F=4.361, p<0.0001^{*}$ \\
Final Thoracic & Healthy H. sapiens vs P. troglodytes & 0.0295 & $\lambda 0.554, F=1.610, p=0.038^{*}$ \\
& & Pathological H. sapiens vs Healthy H. sapiens & 0.0250 & $\lambda 0.640, F=0.677, p=0.984$ \\
& & Pathological H. sapiens vs P. troglodytes & 0.0401 & $\lambda 0.453, F=1.889, p=0.013^{*}$ \\
First Lumbar & Healthy H. sapiens vs P. troglodytes & 0.0247 & $\lambda 0.536, F=1.753, p=0.020^{*}$ \\
& \multirow{2}{*}{$1-24(94.6 \%)$} & Pathological H. sapiens vs Healthy H. sapiens & 0.0305 & $\lambda 0.518, F=7.29, p=0.819$ \\
& & Pathological H. sapiens vs P. troglodytes & 0.0474 & $\lambda 0.466, F=2.295, p<0.001^{*}$ \\
\hline
\end{tabular}


Table 4 Results of the second set of analyses. Procrustes distances and MANOVAs were used to compare pathological H. sapiens vertebrae with healthy $H$. sapiens and $P$. troglodytes vertebrae. Procrustes distances were generated from the PCs that accounted for $\geq 95 \%$ of the shape variance. Those PCs were also used in the MANOVAs. Analyses are grouped on the basis of vertebral type and arranged by the types' position in the vertebral column. $P C s=$ Number of retained PCs plus the percentage of shape variance they explain. PD = Procrustes distance

\begin{tabular}{|c|c|c|c|c|}
\hline Vertebra & PCs & Comparison & PD & MANOVA \\
\hline Penultimate Thoracic & $1-36(95.0 \%)$ & $\begin{array}{l}\text { Pathological } H \text {. sapiens vs Healthy } H \text {. sapiens } \\
\text { Pathological } H \text {. sapiens vs } P \text {. troglodytes } \\
\text { Healthy } H \text {. sapiens vs } P \text {. troglodytes }\end{array}$ & $\begin{array}{l}0.0320 \\
0.0473 \\
0.0708\end{array}$ & $\begin{array}{l}\lambda 0.509, F=1.850, p=0.014^{*} \\
\lambda 0.609, F=0.570, p=0.810 \\
\lambda 0.314, F=3.404, p<0.0001^{* * *}\end{array}$ \\
\hline Final thoracic & $1-38,(95.1 \%)$ & $\begin{array}{l}\text { Pathological } H \text {. sapiens vs Healthy } H \text {. sapiens } \\
\text { Pathological } H \text {. sapiens vs } P \text {. troglodytes } \\
\text { Healthy } H \text {. sapiens vs } P \text {. troglodytes }\end{array}$ & $\begin{array}{l}0.0218 \\
0.0478 \\
0.0540\end{array}$ & $\begin{array}{l}\lambda 0.506, F=2.027, p=0.004^{*} \\
\lambda 0.482, F=1.355, p=0.159 \\
\lambda 0.387, F=2.586, p<0.0001^{* * *}\end{array}$ \\
\hline First Lumbar & $1-36(95.2 \%)$ & $\begin{array}{l}\text { Pathological H. sapiens vs Healthy } H \text {. sapiens } \\
\text { Pathological H. sapiens vs } P \text {. troglodytes } \\
\text { Healthy H. sapiens vs } P \text {. troglodytes }\end{array}$ & $\begin{array}{l}0.0290 \\
0.0682 \\
0.0813\end{array}$ & $\begin{array}{l}\lambda 0.548, F=1.741, p=0.022^{*} \\
\lambda 0.248, F=2.525, p=0.006^{*} \\
\lambda 0.399, F=3.146, p<0.0001^{*}\end{array}$ \\
\hline
\end{tabular}

3981a, which indicated that the shape difference between pathological $H$. sapiens and SK 3981a is greater than the shape difference between healthy $H$. sapiens and SK 3981a.

The other prediction involving the fossil hominin specimens was that the pathological $H$. sapiens vertebrae should be equally similar to the healthy $H$. sapiens and $H$. neanderthalensis vertebrae. This prediction was not supported by any of the relevant comparisons. In all six of the analyses that involved the $H$. neanderthalensis specimens, the pathological $H$. sapiens vertebrae were more similar to the $H$. neanderthalensis vertebrae than were the healthy $H$. sapiens vertebrae.

\section{Discussion and conclusions}

The present paper reports three sets of analyses designed to evaluate the Ancestral Shape Hypothesis for intervertebral disc herniation, which contends that individuals whose vertebrae are towards the ancestral end of the range of shape variation within $H$. sapiens have a greater propensity to develop the condition than other individuals. In the first set of analyses, we found that the bodies, pedicles, and laminae of the lower thoracic and upper lumbar vertebrae of pathological and healthy $H$. sapiens differ significantly in shape, and that the differences are such that pathological $H$. sapiens vertebrae are

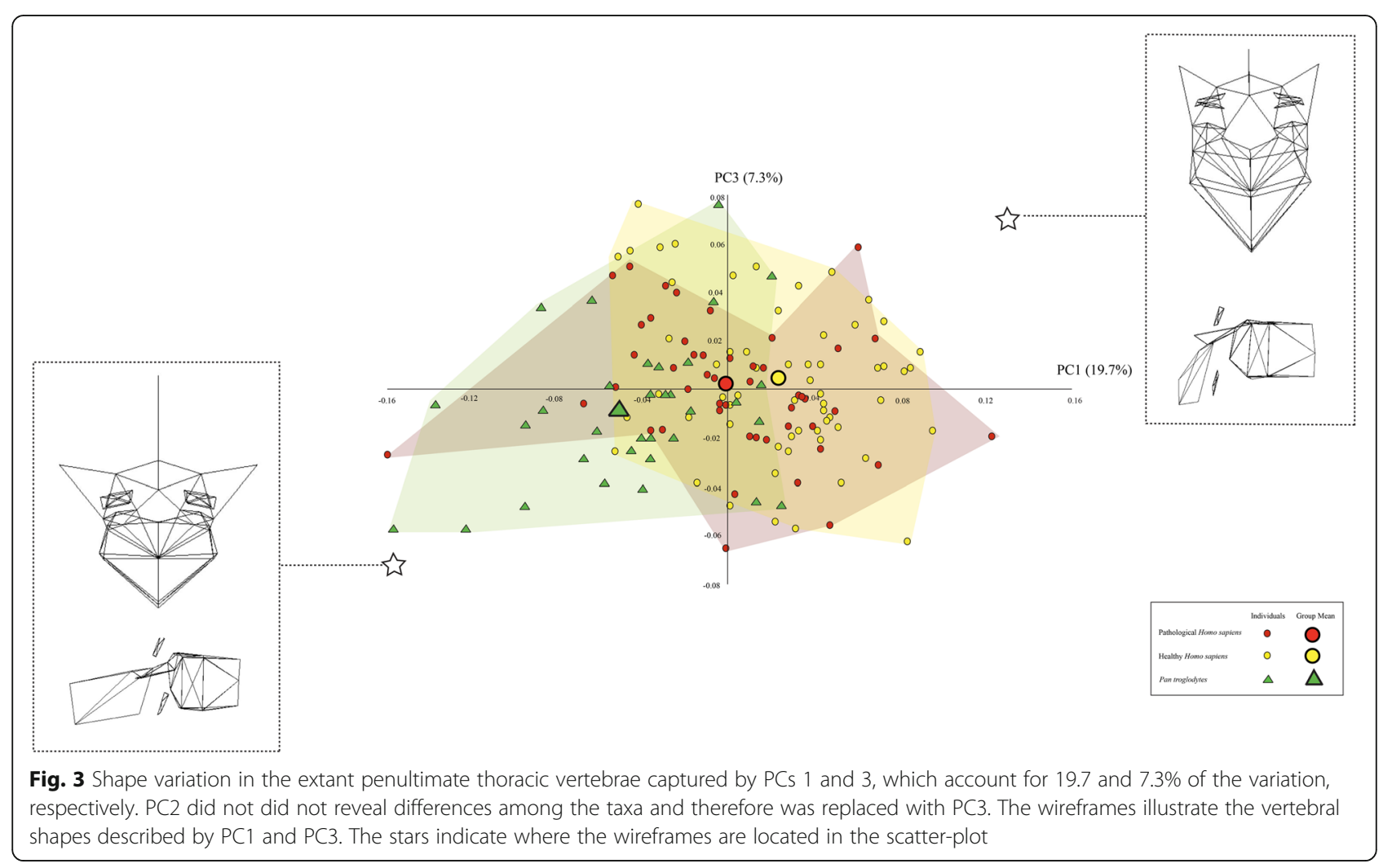




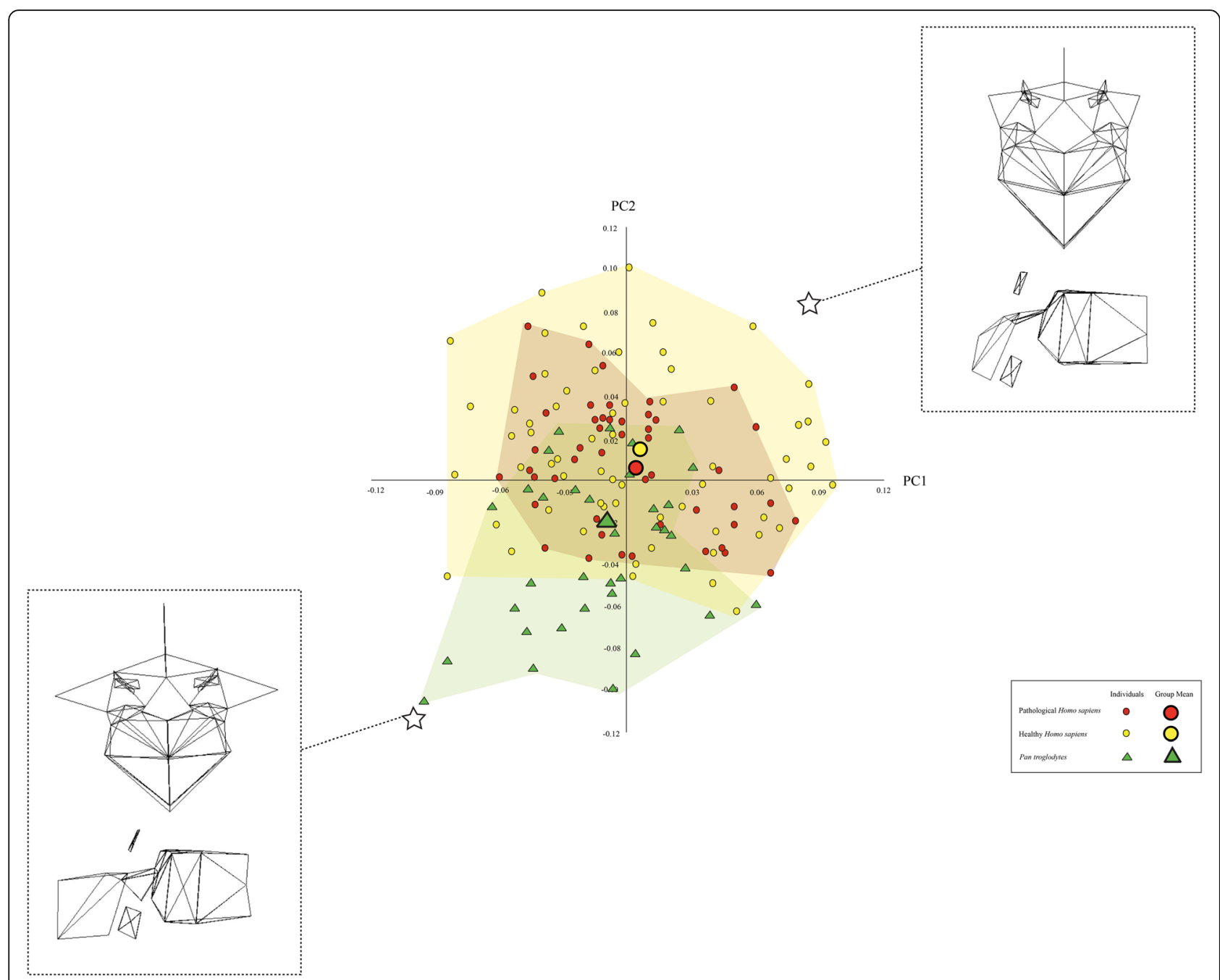

Fig. 4 Shape variation in the extant final thoracic vertebrae captured by PCs 1 and 2, which account for 15 and 12.7\% of the variation, respectively. The wireframes illustrate the vertebral shapes described by PC1 and PC2. The stars indicate where the wireframes are located in the scatter-plot

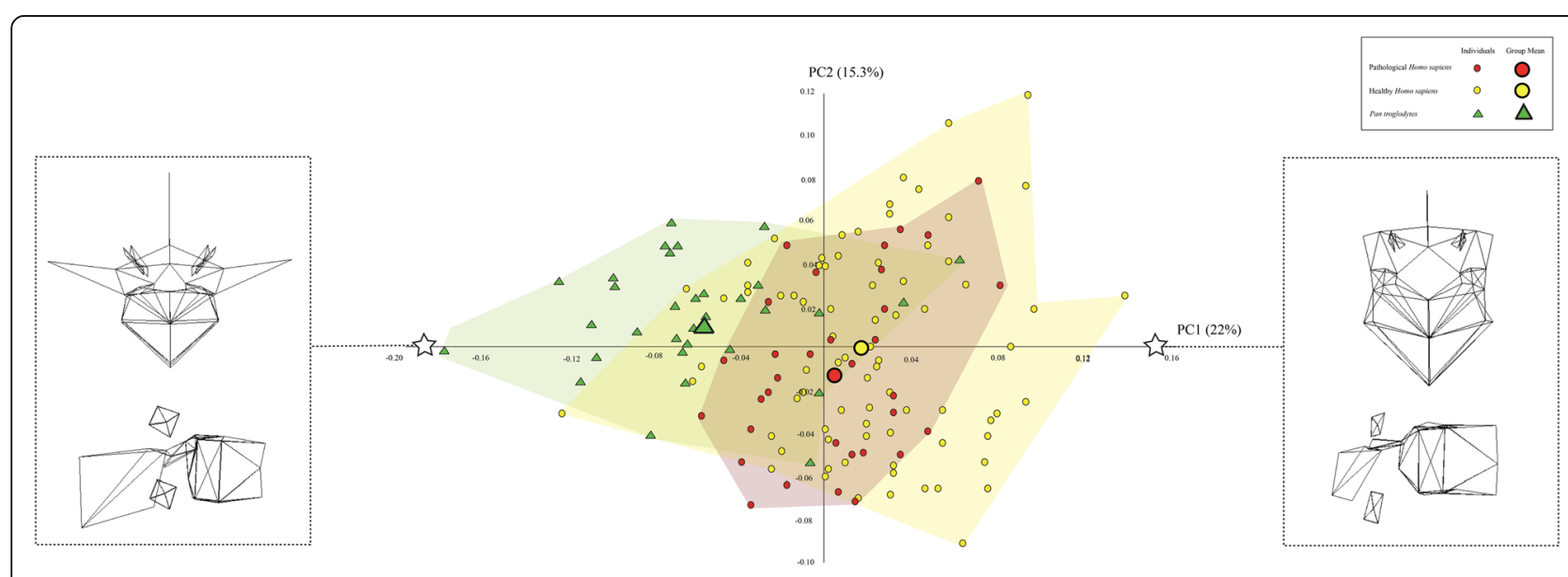

Fig. 5 Shape variation in the extant first lumbar vertebrae captured by PCs 1 and 2, which account for $22.0 \%$ and $15.3 \%$ of the variation, respectively. The wireframes illustrate the vertebral shapes described by PC1. The stars indicate where the wireframes are located in the scatter-plot 
Table 5 Results of the third set of analyses. Procrustes distances were used to compare the mean of the sample of pathological $H$. sapiens vertebrae with the mean shapes of the healthy $H$. sapiens and $P$. troglodytes vertebrae samples, and with the fossil hominin vertebra. Analyses are grouped on the basis of the fossil specimen they included and are arranged in natural sort order and then by position in the vertebral column. PCs = Number of retained PCs plus the percentage of shape variance they explain. PD $=$ Procrustes distance

Fossil specimen (species)
Kebara 2 penultimate thoracic (Homo neanderthalensis)

Kebara 2 final thoracic (Homo neanderthalensis)

Kebara 2 first lumbar (Homo neanderthalensis)

MH1 first lumbar (Australopithecus sediba)

Shanidar 3 penultimate thoracic (Homo neanderthalensis)

Shanidar 3 final thoracic (Homo neanderthalensis)

Shanidar 3 first lumbar (Homo neanderthalensis)

SK853 final thoracic (Paranthropus robustus)

SK3981a final thoracic (Paranthropus robustus)

Sts-14 penultimate thoracic (Australopithecus africanus)

Sts-14 final thoracic (Australopithecus africanus)

Sts-14 first lumbar (Australopithecus africanus)

U.W. 101-1733 penultimate thoracic (Homo naledi)

PCs
PCs 1-25 (95.2\%)
PCs 1-42 (95.1\%)

PCs 1-38

(95.2\%)

PCs 1-38 (95.2\%)

PCs 1-25(95.2\%)

PCs 1-42 (95.1\%)

PCs 1-38 (95.2\%)

PCs 1-42 (95.1\%)

PCs 1-42 (95.1\%)

PCs 1-40 (95.1\%)

PCs $1-42(95.1 \%)$

PCs 1-38 (95.2\%)

PCs $1-25(95.2 \%)$

Comparison PD

Pathological H. sapiens vs $P$. troglodytes $\quad 0.0879$

Healthy $H$. sapiens vs $P$. troglodytes $\quad 0.1047$

Pathological H. sapiens vs Kebara 2 0.0179

Healthy H. sapiens vs Kebara 20.0283

Pathological H. sapiens vs $P$. troglodytes $\quad 0.0681$

Healthy $H$. sapiens vs $P$. troglodytes 0.0729

Pathological H. sapiens vs Kebara $2 \quad 0.0222$

Healthy H. sapiens vs Kebara 20.0226

Pathological H. sapiens vs $P$. troglodytes $\quad 0.1098$

Healthy $H$. sapiens vs $P$. troglodytes 0.1134

Pathological H. sapiens vs Kebara 2

Healthy H. sapiens vs Kebara 20.0552

Pathological H. sapiens vs P. troglodytes $\quad 0.1098$

Healthy $H$. sapiens vs $P$. troglodytes 0.1134

Pathological H. sapiens vs MH1 0.0451

Healthy $H$. sapiens vs MH1 0.0561

Pathological H. sapiens vs P. troglodytes $\quad 0.0879$

Healthy $H$. sapiens vs $P$. troglodytes 0.1047

Pathological H. sapiens vs Shanidar $3 \quad 0.0269$

Healthy H. sapiens vs Shanidar $3 \quad 0.0329$

0.0681

0.0729

0.0188

0.0202

0.1098

0.1134

0.0365

0.0468

0.0681

0.0729

0.0377

0.0404

0.0681

0.0729

0.0464

0.0450

0.0879

0.1047

0.0435

0.0453

0.0681

0.0729

0.0244

0.0270

0.1098

0.1134

0.0300

Healthy $H$. sapiens vs Sts-14 0.0388

0.0879

0.1047

0.0138

0.0287 
closer in shape to $P$. troglodytes vertebrae than are healthy $H$. sapiens vertebrae. The second set of analyses, which included data from additional parts of the vertebrae, also showed that pathological $H$. sapiens vertebrae are closer in shape to $P$. troglodytes vertebrae than are healthy $H$. sapiens vertebrae. The final set of analyses indicated that pathological $H$. sapiens vertebrae are generally closer in shape to the vertebrae of a number of extinct hominin specimens than are healthy $H$. sapiens vertebrae. Together, these findings suggest that the vertebrae of people who suffer from intervertebral disc herniation tend to fall at the ancestral end of the range of shape variation within $H$. sapiens. This supports the Ancestral Shape Hypothesis [15].

In a previous study, we found that compared to healthy $H$. sapiens vertebrae, pathological $H$. sapiens and $P$. troglodytes vertebrae have relatively smaller neural foramina, shorter, wider pedicles, and rounder vertebral bodies [15]. The 3D data reported here support the existence of these differences and reveal some additional ones, especially in the thoracic vertebrae. In both thoracic and the first lumbar, we found that the vertebral bodies of pathological $H$. sapiens and $P$. troglodytes vertebrae are more ventrally wedged than healthy $H$. sapiens vertebrae. In addition, compared to healthy $H$. sapiens vertebrae, the thoracic vertebrae of pathological $H$. sapiens and P. troglodytes vertebrae tend to have longer transverse processes that project more in both the cranial and lateral directions, and longer spinous processes that are more cranially oriented and have craniocaudally taller tips.

Of the additional putative ancestral traits, perhaps the most noteworthy is the increased ventral wedging of the first lumbar vertebra relative to those of healthy $H$. sapiens. Greater ventral wedging in lumbar vertebrae can be expected to result in a smaller lumbar lordosis angle, i.e. a straighter lower back [87]. Hence, our results indicate that people who are prone to intervertebral disc herniation tend to have a straighter back than unaffected $H$. sapiens and suggest that this is an ancestral trait. Both of these hypotheses are supported by the available data on lumbar lordosis angle in $H$. sapiens, $P$. troglodytes, and extinct hominins. The average lumbar lordosis angle for healthy humans is $51^{\circ}$ [88]. Few data on $P$. troglodytes are available but those we have suggest that chimpanzees have a lumbar lordosis angle of around $22^{\circ}$ [89]. Recently, Been et al. [88, 90-92] and Gomez-Olivencia et al. [93] estimated the lumbar lordosis angle of the $A$. africanus individual Sts-14 and several Neanderthal specimens. They found that Sts-14 would have had a lumbar lordosis angle of $43^{\circ}$, while the average they calculated for the Neanderthal specimens is $29^{\circ}$. Haeusler et al. [94] have also recently reconstructed the lordosis angle of a Neanderthal specimen, La Chapelle-aux-Saints 1 . They found that its lordosis angle is $52^{\circ}$, which is close to the average of healthy $H$. sapiens. The differences in estimated lumbar lordosis angles for $H$. neanderthalensis may indicate that the extent of lordosis varied considerably in Neanderthals. Alternatively, it may be the case that the difference in methodology between the studies caused error in one or more reconstructions. Significantly for present purposes, modern humans with intervertebral disc hernias have been found to have an average lumbar lordosis angle of $37^{\circ}[95,96]$. Thus, the pathological $H$. sapiens value not only falls between those for healthy H. sapiens and P. troglodytes, it lies closer to Been et al.'s [88, 90-92] and Gomez-Olivencia et al.'s [93] estimates for the australopiths and $H$. neanderthalensis than to the value for healthy H. sapiens.

Why might the putative ancestral traits predispose individuals to develop intervertebral disc herniation? As we noted in our 2015 paper [15], a possible functional explanation for the association between intervertebral disc herniation and vertebral shape is provided by Harrington et al. [97]. These authors suggest that the diameter of the vertebral disc influences its ability to withstand tension during compression. Their argument is based on LaPlace's law [98], which states that the ability of a fluid-filled tube to withstand tension decreases with increasing radius. According to Harrington et al. [97], the rounder bodies of pathological vertebrae would have larger diameters than the more heart-shaped bodies seen in healthy vertebrae, making the intervertebral disc less able to withstand stress (Fig. 6) [15, 98, 99].

We explained earlier that the more pronounced ventral wedging of the first lumbar vertebrae of pathological humans would result in a lumbar spine with a smaller lumbar lordosis angle [87], and showed that this is supported by studies in which lumbar lordosis angle has been measured in living humans $[95,96]$. The authors of the latter studies assumed that the smaller lumbar lordosis angle of the pathological individuals was a consequence of disc degeneration, especially loss of disc height $[95,96]$. Our findings challenge this idea by suggesting that the small lumbar lordosis angle in pathological individuals is connected with wedging of the ventral body and therefore is present before herniation. If this is the case, then it is possible that a relatively low lumbar lordosis angle predisposes an individual to intervertebral disc hernias. A potential biomechanical explanation for this is that lumbar lordosis is thought to absorb the compressive loads acting on the spine during bipedalism $[47,100,101]$. Thus, a smaller lumbar lordosis angle may decrease the ability of the lower spine to withstand compressive loads.

The shape of the posterior vertebral elements may also influence an individual's susceptibility to intervertebral disc herniation. To reiterate, we found that compared to 
Healthy Homo sapiens vertebrae

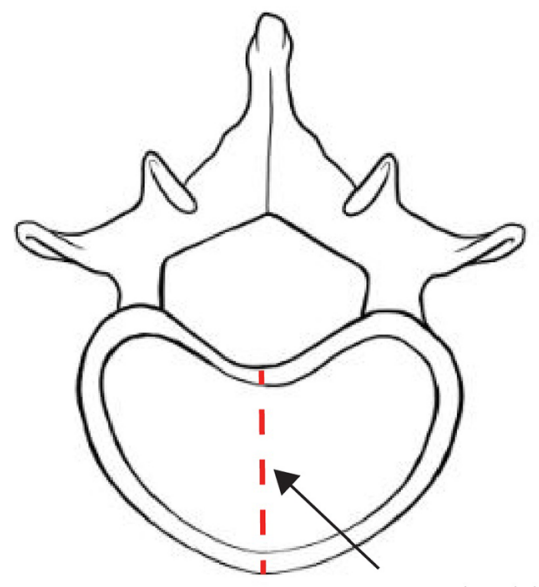

Pathological Homo sapiens vertebrae

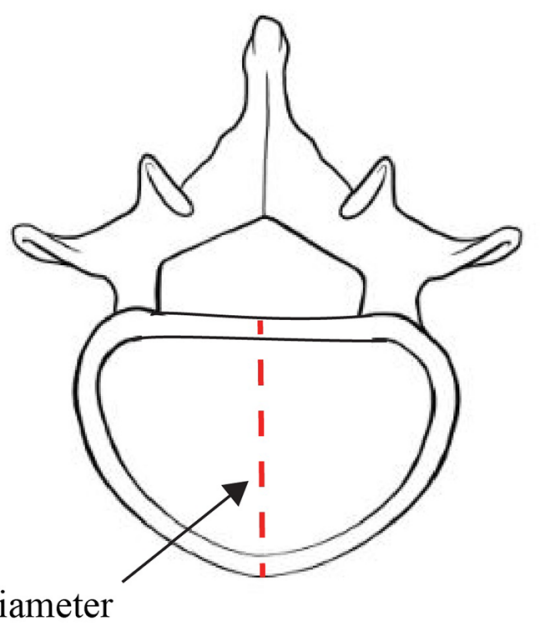

Fig. 6 Cartoon illustrating the differences in diameter between a heart-shaped vertebral body and a more circular vertebral body

healthy $H$. sapiens vertebrae, pathological $H$. sapiens vertebrae tended to have shorter pedicles and laminae. The pedicles and laminae act as structural buttresses for the vertebral body and play an important role in load bearing during axial compression [102-104], and it has been hypothesized that the shorter pedicles and laminae identified in vertebrae with Schmorl's nodes may be less able to adequately buttress these loads than the longer pedicles and laminae of healthy human vertebrae $[15,99,105]$.

In addition, we found that pathological thoracic vertebrae tended to have relatively longer, cranially-oriented spinous processes and longer, cranio-laterally projecting transverse processes. Comparative analyses suggest that the length and orientation of spinous processes relate to spinal mobility and stability [46, 106-110]. Long, cranially-oriented spinous processes are found in many arboreal monkey species and are thought to allow for a greater amount of dorsal mobility in the spine, while short, caudally oriented spinous processes are associated with a less mobile, more stable spine [46, 93, 110-114]. Similarly, mediolaterally longer transverse processes would allow for lateral flexion in the lower spine [46, $112,113]$, and transverse processes that project more laterally may be less able to maintain lumbar lordosis than those that project dorsally $[43,46,88,92,93,112]$. Together, these observations suggest that the longer, cranially oriented spinous processes and longer, laterally projecting transverse processes of vertebrae with Schmorl's nodes may increase the dorsal mobility of the spine compared to shorter, cranially/cranially-dorsally oriented processes of healthy vertebrae. This in turn implies that the traits in question may not provide adequate stability during bipedalism, and - in combination with the short pedicles and laminae and circular, ventrally wedged vertebral bodies - may predispose individuals to intervertebral disc hernias.

That the two $P$. robustus final thoracic vertebrae, SK 853 and SK 3981a, yielded conflicting results was unexpected. To reiterate, the comparison that involved SK 853 supported the relevant test prediction while the comparison that involved SK 3981a did not. Given that the specimens are assigned to the same species, it is surprising that they yielded conflicting results. There are three obvious potential explanations for this. One is that, even though SK 3981a appeared normal to us and to the specimen's original describer [56], it is either pathological or deformed and, therefore, is more similar to healthy $H$. sapiens vertebrae than it should be. The second possibility is that SK 853 and SK 3981a yielded different results because SK 853 is a juvenile specimen. Under this hypothesis, the developmental status of SK 853 caused it to be misleadingly similar to the other early hominin specimens in the sample and to the pathological $H$. sapiens vertebrae. The third possibility is that SK 3981a and SK 853 do not in fact belong to the same species. Ascertaining which of these hypotheses is most likely to be correct will require further research.

The results of the analyses featuring the Neanderthal specimens were also unexpected. We predicted that the pathological $H$. sapiens vertebrae would be intermediate between the $H$. neanderthalensis and healthy $H$. sapiens vertebrae, but the pathological $H$. sapiens vertebrae were in fact closer to the $H$. neanderthalensis vertebrae than to the healthy $H$. sapiens vertebrae. Given that the analyses in question involved six different Neanderthal specimens, we think it is unlikely that either unrecognized pathology or deformation caused the analyses to fail to support the prediction. The only other obvious 
explanation is that the test prediction was wrong. As we explained earlier, we based the prediction on the fact that it is widely accepted that Neanderthals were obligate bipeds like modern humans. It seemed reasonable to suppose therefore that Neanderthal vertebrae should have similar bipedalism-related adaptations as modern human vertebrae. However, the analyses suggest that this is not the case. In all the relevant analyses, the distance between the pathological $H$. sapiens mean and the $H$. neanderthalensis mean was smaller than the distance between the healthy $H$. sapiens mean and the $H$. neanderthalensis mean. Given the results of the first two sets of analyses, this not only indicates that Neanderthal lower thoracic and lumbar vertebrae are not identical to their healthy modern human counterparts, it also suggests that they have a number of plesiomorphic features. This raises the possibility that Neanderthals may have been prone to intervertebral disc herniation. Interestingly, Haeusler [115] has recently reported that the La Chapelle-aux-Saints 1 Neanderthal specimen has Schmorl's nodes in its eighth, ninth, and tenth thoracic vertebrae.

With regard to future research, three tasks suggest themselves. The first and most obvious is to test the foregoing biomechanical hypotheses linking the ancestral traits with propensity to develop intervertebral disc herniation. This could be accomplished by using medical imaging technology and 3D morphometrics to investigate the interaction between bipedalism, vertebral shape, and the soft tissues of the spine in pathological and healthy humans.

It would also be useful to perform analyses similar to the current one on individuals with other spinal pathologies. Spondylolysis - a cleft in the neural arch caused by a fatigue fracture at the site of the pars interarticularis [116] - would be an obvious next target because it has been linked to both bipedalism and vertebral morphology [16]. Specifically, it would be interesting to explore how those vertebral traits associated with spondylolysis identified by Ward and colleagues [16-19] and Masharawi et al. $[19,20]$ relate to $H$. sapiens and non-human ape vertebral variation. The findings of such a study could provide important information to help researchers and clinicians understand how and why posture and locomotion can influence traumatic conditions like spondylolysis.

Lastly, it would be helpful to test the most basic of the assumptions made by the Ancestral Shape Hypothesis, which is that the causal arrow goes from vertebral shape to intervertebral disc herniation rather than vice versa. There are reasons to believe this is the case. Most notably, the shape of the vertebral foramen is known not to change once the neural arch fuses to the vertebral body $[115,116]$. This implies that the pedicles, laminae, and vertebral body, which form the vertebral foramen, also do not change shape once the neural arch fuses to the vertebral body. However, the assumption still needs to be tested. It seems likely that doing so will require a longitudinal study.

\section{Supplementary information}

Supplementary information accompanies this paper at https://doi.org/10. 1186/s12862-019-1550-9.

Additional file 1: Table S1. Results of the pooled-taxa regressions to analyse allometry. Procrustes coordinates were regressed on the log of centroid size in MorphoJ.

\section{Acknowledgements}

We thank the following institutions for access to the specimens used in this study: Naturhistorisches Museum, Vienna, Austria; Museum für Naturkunde, Berlin, Germany; University of Zürich's Anthropological Institute \& Museum, Zürich, Switzerland; the University of Copenhagen's Department of Forensic Medicine, Copenhagen, Denmark; the Smithsonian Institute Museum of Natural History, Washington, DC, USA; and the Cleveland Museum of Natural History, Cleveland, Ohio, USA. We also thank Allowen Evin for her assistance with the analyses. This study was supported by the Social Sciences and Humanities Research Council of Canada (895-2011-1009), Canada Research Chairs Program (228117 and 231256), Canada Foundation for Innovation (203808 and 36801), British Columbia Knowledge Development Fund (862-804231 and 962-805808), Simon Fraser University (14518), MITACS (IT03519), the Wenner-Gren Foundation (62447), and Marie Skłodowska-Curie Actions (SAR10359)

\section{Authors' contributions}

KAP, KD, DAW, USV, and MC designed the study. KAP, MC, and KD obtained funding for the study. KAP collected and analyzed the data. KAP and MC interpreted the results and drafted the manuscript. KAP, KD, DAW, USV, and MC edited the manuscript. All authors read and approved the final manuscript.

\section{Funding}

Our research was supported by the Social Sciences and Humanities Research Council of Canada (895-2011-1009), Canada Research Chairs Program (228117 and 231256), Canada Foundation for Innovation (203808 and 36801), British Columbia Knowledge Development Fund (862-804231 and 962-805808), MITACS (IT03519), the Wenner-Gren Foundation (62447), Simon Fraser University (14518), the University of Liverpool, and Marie Skłodowska-Curie Actions (SAR10359).

\section{Availability of data and materials}

The datasets used and analysed during the current study are available from the corresponding author on reasonable request.

Ethics approval and consent to participate Not applicable.

\section{Consent for publication}

Not applicable.

\section{Competing interests}

The authors declare that they have no competing interests.

\section{Author details}

'Department of Archaeology, Classics and Egyptology, University of Liverpool, 14 Abercromby Square, Liverpool L69 7WZ, UK. ${ }^{2}$ Department of Archaeology, Simon Fraser University, 8888 University Dr, Burnaby, BC V5A 156, Canada. ${ }^{3}$ Department of Archaeology, School of Geosciences, University of Aberdeen, St Mary's, Elphinstone RoadScotland, UK AB24 3UF Aberdeen. ${ }^{4}$ Department of Anthropology, University of British Columbia, 6303 NW Marine Drive, Vancouver, BC V6T 1Z1, Canada. ${ }^{5}$ Biomedical Center, University of Iceland, Læknagarður, Vatnsmýrarvegi 16, 101, Reykjavík, Iceland. 


\section{Received: 9 April 2019 Accepted: 29 November 2019} Published online: 16 December 2019

\section{References}

1. Walker BF. The prevalence of low back pain: a systematic review of the literature from 1966 to 1998. J Spinal Disord. 2000;13:205-17.

2. Balague F, Mannion AF, Pellise F, Cedraschi C. Non-specific low back pain. Lancet. 2012;379:482-91.

3. Buchbiner R, Blyth FM, March LM, Brooks P, Woolf AD, Hoy DG. Placing the global burden of low back pain in context. Best Pract Res CI Rh. 2013;27: 575-89.

4. Webb R, Brammah T, Lunt M, Urwin M, Allison T, Symmons D. Prevalence and predictors of intense, chronic, and disabling neck and back pain in the UK general population. Spine. 2003;28:1195-202.

5. Maniadakis N, Gray A. The economic burden of back pain in the UK. Pain. 2000;84:95-103.

6. Donaldson L. Annual report of the chief medical officer on the state of public health. London: Department of Health; 2008.

7. Ricci JA, Stewart WF, Chee E, Leotta C, Foley K, Hochberg MC. Back pain exacerbations and lost productive time costs in United States workers. Spine. 2006:31:3052-60.

8. Jurmain R. Trauma, degenerative disease, and other pathologies among the Gombe chimpanzees. Am J Phys Anthropol. 1989;80:229-37.

9. Lovell N. Patterns of injury and illness in the great apes: a skeletal analysis. Washington, DC: Smithsonian Institution; 1990.

10. Keith A. Hunterian lectures on man's posture: its evolution and disorders. Brit Med J. 1923;1:499-502.

11. Jurmain RD. Degenerative joint disease in African great apes: an evolutionary perspective. J Hum Evol. 2000;39:185-203.

12. Sparrey CJ, Bailey JF, Safaee M, Clark AJ, Lafage V, Schwab F, Smith JS, Ames CP. Etiology of lumbar lordosis and its pathophysiology: a review of the evolution of lumbar lordosis, and the mechanics and biology of lumbar degeneration. J Neurosurg. 2014;36:E1.

13. Latimer B. The perils of being bipedal. Ann Biomed Eng. 2005;33:3-6.

14. Filler AG. Emergence and optimization of upright posture among hominiform hominoids and the evolutionary pathophysiology of back pain. Neurosurg Focus. 2007:23:E4

15. Plomp KA, Strand Viðarsdóttir U, Weston D, Dobney K, Collard M. The ancestral shape hypothesis: an evolutionary explanation for the occurrence of intervertebral disc herniation in humans. BMC Evol Biol. 2015;15:68.

16. Ward CV, Latimer B. Human evolution and the development of spondylolysis. Spine. 2005;30:1808-14.

17. Ward CV, Latimer B, Alander DH, Parker J, Ronan JA, Holden AD, Sanders C. Radiographic assessment of lumbar facet distance spacing and spondylolysis. Spine. 2007;32:E85-8

18. Ward CV, Mays SA, Child S, Latimer B. Lumbar vertebral morphology and isthmic spondylolysis in a British medieval population. Am J Phys Anthropol. 2010:141:273-80

19. Masharawi Y, Alperovitvh-Najenson D, Steinberg N, Dar G, Peleg S, Rothschild B, Salame K, Hershkovtiz I. Lumbar facet orientation in spondylolysis: a skeletal study. Spine. 2007;32:E176-80.

20. Masharawi Y. Lumbar shape characterization of the neural arch and vertebral body in spondylolysis: a comparative skeletal study. Clin Anat. 2012;25:224-30

21. Chung SB, Lee S, Kim H, Lee SH, Kim ES, Eoh W. Significance of interfacet distances, facet joint orientation, and lumbar lordosis in spondlylolysis. Clin Anat. 2012;25:391-7.

22. Meyer M. The cervical vertebrae of KSD-VP-1/1. In: Haile-Selassie Y, Su D, editors. editors The postcranial anatomy of Australopithecus afarensis. Dordrecht: Springer; 2016. p. 63-111.

23. Been E, Ling L, Hunter DJ, Kalichman L. Geometry of the vertebral bodies and the intervertebral disc in lumbar segments adjacent to spondylolysis and spondylolisthesis: a pilot study. Euro Spine J. 2011:20:1159-65.

24. Jensen MC, Brant-Zawadzki MN, Obuchowski N, Modic MT, Malkasian D, Ross JS. Magnetic resonance imaging of the lumbar spine in people without back pain. N Engl J Med. 1994:331:69-73.

25. Kyere KA, Than KD, Wang AC, Rahman SU, Valdivia-Valdivia JM, La Marca F, Park P. Schmorl's nodes. Eur Spine J. 2012;21:2115-21.

26. Diehn FE, Maus TP, Morris JM, Carr CM, Kotsenas AL, Luetmer PH, Lehman $V T$, Thielen KR, Nassr A, Wald JT. Uncommon manifestations of intervertebral disc pathological conditions. RadioGraphics. 2016;36:801-23.
27. Wagner AL, Murtagh FR, Arrington JA, Stallworth D. Relationship of Schmorl's nodes to vertebral body endplate fractures and acute disk extrusions. Am J Neuroradiol. 2000;21:276-81.

28. Williams FM, Manek NJ, Sambrook PN, Spector TD, Macgregor AJ. Schmorl's nodes: common, highly heritable, and related to lumbar disc disease. Arthritis Rheum. 2007;57:855-60.

29. Faccia KJ, Williams RC. Schmorl's nodes: clinical significance and implications for the bioarchaeological record. Int J Osteoarchaeol. 2008:18:28-44.

30. Schmorl G, Junghans $\mathrm{H}$. The human spine in health and disease. New York: Grune and Stratton; 1971.

31. Richmond BG, Begun DR, Strait DS. Origin of human bipedalism: the knuckle-walking hypothesis revisted. Am J Phys Anthropol. 2001;116:70-105.

32. Thorpe SKS, Holder RL, Crompton RH. Origin of human bipedalism as an adaptation for locomotion on flexible branches. Science. 2007;316:1328-31.

33. Lovejoy O, Suwa G, Simpson SW, Matternes JH, White T. The great divides: Ardipithecus ramidus reveals the postcrania of our last common ancestors with African apes. Science. 2009:326:73-106.

34. Cardini A. Missing the third dimension in geometric morphometrics: how to assess if 2D images really are a good proxy for 3D structures? Hystrix. 2014; 25:73-81.

35. Scheuer L, Black S. Developmental juvenile osteology. London: Academic Press; 2000.

36. Sanders WJ, Bodenbender BE. Morphometric analysis of lumbar vertebra UMP 67-28: implications for spinal function and phylogeny of the Miocene Moroto hominoid. J Hum Evol. 1991;26:203-37.

37. Shapiro L. Functional morphology of the vertebral column in primates. In: Gebo DL. Postcranial adaptation in non-human primates. Dekalb: Northern Illinois University Press; 1993.

38. Schultz AH. The skeleton of the trunk and limbs of higher primates. Hum Biol. 1930:2:303-48.

39. Schultz AH. Vertebral column and thorax. Primatologica. 1961;4:1-66.

40. Schultz AH, Straus WL. The numbers of vertebrae in primates. Proc Am Phil Soc. 1945;89:601-26

41. Williams S. Placement of the diaphragmatic vertebra in Catarrhines: implications for the evolution of dorsostability in hominoids and bipedalism in hominins. Am J Phys Anthropol. 2012;148:111-22.

42. Williams S, Middleton ER, Villamil Cl, Shattuck MR. Vertebral numbers and human evolution. Yrbk Phys Anthropol. 2016;159:S19-36.

43. Haeusler M, Martelli SA, Boeni T. Vertebrae numbers of the early hominid lumbar spine. J Hum Evol. 2002;43:621-43.

44. Haeusler M, Schiess R, Boeni T. New vertebral and rib material point to modern bauplan of the Nariokotome Homo erectus skeleton. J Hum Evol. 2011;61:575-82.

45. Whitcome KK. Functional implications of variation in lumbar vertebral count among hominins. J Hum Evol. 2012;62:486-97.

46. Russo GA. Prezygapophyseal articular facet shape in the Catarrhine thoracolumbar vertebral column. Am J Phys Anthropol. 2010;142:600-12.

47. Whitcome KK, Shapiro $\sqcup$, Lieberman DE. Fetal load and the evolution of lumbar lordosis in bipedal hominins. Nature. 2007:450:1075-80.

48. Ankel F. Morphologie von Wirbelsaule und Brustkorb. Primatologia. 1972;4:1-120.

49. Shapiro L. Functional morphology of the primate spine with special reference to orthograde posture and bipedal locomotion. State University of New York at Stony Brooke: Doctoral dissertation; 1991.

50. Boszczyk BM, Boszczyk AA, Putz R. Comparative and functional anatomy of the mammalian lumbar spine. Anat Rec. 2001:264:157-68.

51. Bogduk N, Twomey L. Clinical anatomy of the lumbar spine and sacrum. Churchill: Livingstone; 2005.

52. Washburn SL. Behaviour and human evolution. In: Washburn SL, editor. editor Classification and human evolution. Chicago: Aldine; 1963. p. 190-203.

53. Shapiro L. Functional morphology of Indrid lumbar vertebrae. Am J Phys Anthropol. 1995;98:323-42

54. Lovejoy 0 . The natural history of human gait and posture part 1. Spine and Pelvis. Gait Post. 2005;21:95-112.

55. Nakatsukasa M, Kunimatsu Y, Nakano Y, Ishida H. Vertebral morphology of Nacholapithecus kerioi based on KNM-BG 35250. J Hum Evol. 2007;52:347-69.

56. Robinson JT. Early hominin posture and locomotion. Chicago and London: University of Chicago Press; 1972

57. Valladas H, Joron LJ, Valladas G, Arensburg B, Bar-Yosef O, Belfer-Cohen A Goldberg P, Laville H, Meignen L, Rak Y, Tchernov E, Tillier AM, Vandermeersch B. Thermoluminescence dates for the Neanderthal burial site at Kebara in Israel. Nature. 1987;330:159-60. 
58. Stewart TD. The Neanderthal skeletal remains from Shanidar cave, Iraq: a summary of findings to date. Proc Am Phil Soc. 1977;121:121-65.

59. Dirks P, Kibii JM, Kuhn BF, Steininger C, Churchill SE, Kramers JD, Pickering R, Farber DL, Meriaux AS, Herries A, King GC, Berger LR. Geological setting and age of Australopithecus sediba from southern Africa. Science. 2010;328:205-8.

60. Dirks P, Roberts EM, Hilbert-Wolf H, Kramers JD, Hawks J, Dosseto A, Duval M, Elliott M, Evans M, Grun R, Hellstrom J, Herries A, Joannes-Boyau R, Makhubela TV, Placzek CJ, Robbins J, Spandler C, Wiersma J, Woodhead J, Berger LR. The age of Homo naledi and associated sediments in the rising star cave, South Africa. eLife. 2017;6:e24231.

61. Soleki RS. Prehistory in Shanidar Valley, northern Iraq. Science. 1963;139:179-93.

62. Berger LR, de Ruiter DJ, Churchill SE, Schmid P, Carlson KJ, Dirks P, Kibii JM. Australopithecus sediba: a new species of Homo-like Australopith from South Africa. Science. 2010;238:195-204.

63. Williams SA, Ostrofsky KR, Frater N, Churchill SE, Schmid P, Berger LR. The vertebral column of Australopithecus sediba. Science. 2013;340:123966-1.

64. Bookstein F. Landmark methods for forms without landmarks: morphometrics of group differences in outline shape. Med Image Anal. 1997;1:225-43

65. Arnqvist G, Martensson T. Measurement error in geometric morphometrics: empirical strategies to assess and reduce its impact on measures of shape. Acta Zool Hung. 1998;44:73-96.

66. Neubauer S, Gunz P, Hublin JJ. The patterns of endocranial ontogenetic shape changes in humans. J Anat. 2009;215:240-55.

67. Neubauer S, Gunz P, Hublin JJ. Endocranial shape changes during growth in chimpanzees and humans: a morphometric analysis of unique and shared aspects. J Hum Evol. 2010;59:555-66.

68. O'Higgins P, Jones N. Tools for statistical shape analysis. York Medical School: Hull; 2006.

69. Harcourt-Smith WEH, Throckmorton Z, Congdon KA, Zipfel B, Deane AS, Drapeau MSM, Churchill SE, Berger LR, DeSilva JM. The foot of Homo nadeli. Nat Commun. 2015;6:8432

70. Slice DE. Geometric morphometrics. Annu Rev Anthropol. 2007;36:261-81.

71. Meindl K, Windhager S, Wallner B, Schaefer K. Second-to-fourth digit ratio and facial shape in boys: the lower the digit ratio, the more robust the face. Proc R Soc B. 2012;279:2457-63.

72. Debat V, Begin M, Legout H, David JR. Allometric and nonallometric components of Drosophila wing shape respond differently to developmental temperature. Evolution. 2003;57:2773-84.

73. Monteiro LR. Multivariate regression models and geometric morphometrics: the search for casual factors in the analysis of shape. Syst Biol. 1999;48:192-9.

74. Klingenberg CP. MorphoJ: an integrated software package for geometric morphometrics. Mol Ecol Resour. 2011;11:353-7.

75. Inc SPSS. SPSS Base 8.0 for windows User's guide. Chicago: SPSS Inc; 2016

76. Baylac M, Frieb M. Fourier descriptors, Procrustes superimposition, and data dimensionality: an example of cranial shape analysis in modern human populations. In: Slice D, editor. Modern Morphometrics in physical anthropology, part 1 theory and methods. New York: Kluwer; 2005.

77. Evin A, Cucci T, Cardini A, Strand Vidarsdottir U, Larson G, Dobney K. The long and winding road: identifying pig domestication through molar size and shape. J Archaeol Sci. 2013;40:735-43.

78. R Development Core Team. R: a language and environment for statistical computing. Vienna: R Foundation for Statistical Computing; 2018.

79. Wood B, Collard M. The changing face of Homo. Evol Anthropol. 1999;8: 195-207.

80. Senut B, Pickford M, Gommery D, Mein P, Cheboi K, Coppens Y. First hominind from the Miocene (Lukeino formation, Kenay). Series IIA - Earth and Planetary Sci. 2001;332:137-44.

81. Harcourt-Smith WEH, Aiello L. Fossils, feet and the evolution of human bipedal locomotion. J Anat. 2004;204:403-16.

82. Crompton R, Vereecke EE, Thorpe SKS. Locomotion and posture from the common hominoid ancestor to fully modern hominins, with special references to the last common panin/hominin ancestor. J Anat. 2008;212:501-43.

83. Kibii JM, Churchill SE, Schmid P, Carlson KJ, Reed ND, de Ruiter D, Berger L. A partial pelvis of Australopithecus sediba. Science. 2011;333:1407-11.

84. DeSilva JM, Holt KG, Churchill SE, Carlson KJ, Walker CS, Zipfel B, Berger L. The lower limb and mechanics of walking in Australopithecus sediba. Science. 2013:340:1232999.

85. Wood BA. Origin and evolution of the genus Homo. Nature. 1992;355:783-90

86. Trinkaus E. Functional aspects of Neanderthal pedal remains. Foot Ankle. 1983;3:377-90.
87. Been E, Barash A, Marom A, Kramer P. Vertebral bodies or discs: which contributes more to human-like lumbar lordosis? Clin Orthop Relat Res. 2010;486:1822-9.

88. Been E, Gomez-Olivencia A, Kramer PA, Barash A. 3D reconstruction of spinal posture of the Kebara 2 Neanderthal. In: Marom A, Hovers E, editors. (eds) Human paleontology and prehistory. Cham, Switzerland: Springer; 2017.

89. Abitbol MM. Evolution of the lumbosacral angle. Am J Phys Anthropol. 1987;72:361-72

90. Been E, Peleg S, Marom A, Barash A. Morphology and function of the lumbar spine of the Kebara 2 Neandertal. Am J Phys Anthropol. 2010;142:549-57.

91. Been E, Gomez-Olivencia A, Kramer PA. Lumbar lordosis of extinct hominins. Am J Phys Anthropol. 2012;147:64-77.

92. Been E, Gomez-Olivencia A, Kramer PA. Brief communication: lumbar lordosis in extinct hominins: implications of the pelvic incidence. Am J Phys Anthropol. 2014:154:307-14.

93. Gómez-Olivencia A, Arlegi M, Barash A, Stock J, Been E. The Neandertha vertebral column 2: the lumbar spine. J Hum Evol. 2017;106:84-101.

94. Haeusler M, Trinkaus E, Fornai C, Müller J, Bonneau N, Boeni T, Frater N. Morphology, pathology, and the vertebral posture of the La Chapelle-auxsaints Neandertal. PNAS. 2019;116:4923-7.

95. Sak GS, Ayoub CM, Domloj NT, Turbay MJ, El-Zein C, Hourani MH. Effect of age and lordotic angle on the level of lumbar disc herniation. Ad Orthop. 2011;2011:950576.

96. Endo K, Suzuki H, Tanaka H, Kang Y, Yamamoto K. Sagittal spinal alignment in patients with lumbar disc herniation. Eur Spine J. 2010;19:435-8.

97. Harrington JF, Sungarian A, Rogg J, Makker VJ, Epstein MH. The relation between vertebral endplates shape and lumbar disc herniations. Spine. 2001:26:2133-8

98. Letić M. Feeling wall tension in an interactive demonstration of Laplace's law. Ad Physiol Ed. 2012;36:176

99. Plomp KA, Roberts CA, Strand VU. Vertebral morphology influences the development of Schmorl's nodes in the lower thoracic vertebra. Am J Phys Anthropol. 2012;149:172-82.

100. Gracovetsky SA, lacono S. Energy transfers in the spinal engine. Med Eng Phys. 1987:9:99-114

101. Farfan HF. Form and function of the musculoskeletal system as revealed by mathematical analysis of the lumbar spine. An essay. Spine. 1995;20:1462-74.

102. El-Khoury GY, Whitten CG. Trauma to the upper thoracic spine: anantomy, biomechanics, and unique imaging features. Am J Roentgen. 1993;160:95-102.

103. Whyne CM, Hu SS, Klisch S, Lotz J. 1998. Effect of the pedicle and posterior arch on vertebral body strength predictions in finite element modeling. Spine. 1998;23:899-907.

104. Adams MA, McNally DS, Chinn H, Dolan P. Posture and the compressive strength of the lumbar spine. Clin Biomech. 1994;9:5-14.

105. Plomp KA, Roberts CA, Strand VU. Does the correlation between Schmorl's nodes and vertebral morphology extend into the lumbar spine? Am J Phys Anthropol. 2012;157:526-34

106. Shapiro LJ, Jungers WL. Back muscle function during bipedal walking in chimpanzee and gibbon: implications for the evolution of human locomotion. Am J Phys Anthropol. 1988;77:201-12

107. Shapiro LJ, Jungers WL. Electromyography of back muscles during quadrupedal and bipedal walking in primates. Am J Phys Anthropol. 1994 93:491-504.

108. Shapiro LJ. Morphological and functional differentiation in the lumbar spine of lorisids and galagids. Am J Primatol. 2007:69:86-102.

109. Shapiro $L$, Simons CVM. Functional aspects of strepsirrhine lumbar vertebral bodies and spinous processes. J Hum Evol. 2002;42:753-83.

110. Shapiro LJ, Seiffert CV, Godfrey LR, Jungers WL, Simons EL, Randia GF. Morphometric analysis of lumbar vertebrae in extinct Malagasy strepsirrhines. American J Phys Anthropol. 2005;128:823-4.

111. Ward C. Functional anatomy of the lower back and pelvis of the Miocene hominoid Proconsul nyanzae from Mfangano Island, Kenya. PhD dissertation, The John Hopkins University; 1991.

112. Sanders WJ. Comparative morphometric study of the australopithecine vertebral series Stw-H8/H41. J Hum Evol. 1998;34:249-302.

113. Argot C. Functional-adaptive anatomy of the axial skeleton of some extant marsupials and the paleobiology of the Paleocene marsupials Mayulestes ferox and Pucadelphys andinus.J Moprhol. 2003:255:279-300.

114. Meyer MR. The cervical vertebrae of KSD-VP-1/1. In: Haile-Selassie Y, Su D, editors. (eds) The postcranial anatomy of Australopithecus afarensis. Vertebrate Paleobiology and Paleoanthropology. Dordrecht: Springer; 2016. 
115. Johnson DR, O'Higgins P, McAndrew TJ. The relationship between age, size, and shape in the upper thoracic vertebrae of the mouse. J Anat. 1998;161: 73-82.

116. Masharawi Y, Salame K. Shape variation of the neural arch in the thoracic and lumbar spine: characterization and relationship with the vertebral body shape. Clin Anat. 2011;24:858-67.

\section{Publisher's Note}

Springer Nature remains neutral with regard to jurisdictional claims in published maps and institutional affiliations.

- fast, convenient online submission

- thorough peer review by experienced researchers in your field

- rapid publication on acceptance

- support for research data, including large and complex data types

- gold Open Access which fosters wider collaboration and increased citations

- maximum visibility for your research: over $100 \mathrm{M}$ website views per year

At $\mathrm{BMC}$, research is always in progress. 